\title{
A EFETIVAÇÃO DOS INSTITUTOS DE PARTICIPAÇÃO POPULAR DIRETA NO BRASIL
}

\author{
Gabriel Santos Rios ${ }^{1}$
}

\begin{abstract}
RESUMO
O presente trabalho visa a propor e a analisar possíveis alternativas para a efetivação dos institutos de participação popular direta no Brasil, adotando como ponto de partida o contraste entre o mandamento constitucional em prol da democracia semidireta (maximalismo democrático) e a escassa utilização dos referendos, plebiscitos e iniciativas populares. Para tanto, realizar-se-á uma revisão bibliográfica mesclada com uma pesquisa documental, promovendo uma análise crítica dos mecanismos formais de participação popular não-intermediada previstos constitucionalmente, dos principais institutos nãoprevistos constitucionalmente e do papel que pode ser desempenhado pela tecnologia na concretização de um modelo deliberativo de democracia, abordando a mitigação do cunhado "dogma da inviabilidade da democracia direta". Conclui-se aventando as bases para uma efetiva democracia participativa no Brasil, incluindo a ampliação do rol dos institutos de participação direta do povo (em âmbito nacional e local), a facilitação do seu uso (através, por exemplo, de meios eletrônicos), o acionamento popular de referendos e plebiscitos e a consolidação da força vinculante das decisões populares, ressalvando, porém, que a utilização ampla de instrumentos que permitam o exercício do poder político pelo povo tão-somente não é bastante para construir um Estado verdadeiramente democrático, apesar de constituir um passo inicial bastante sólido.
\end{abstract}

Palavras-chave: Democracia semidireta. Participação popular direta. Democracia eletrônica.

\section{CONSIDERAÇÕES INICIAIS}

Declara o parágrafo único do artigo $1^{\circ}$ da Constituição Federal de 1988 (BRASIL, 1988): "todo o poder emana do povo, que o exerce por meio de representantes eleitos ou diretamente, nos termos desta Constituição", i.e., a capacidade de exercer a soberania nacional provém do povo, que a realiza de forma mediata ou imediata ${ }^{2}$.

\footnotetext{
${ }^{1}$ Graduando do quarto semestre do curso de Direito da Universidade Estadual de Feira de Santana. E-mail: gabrielsrios@outlook.com.

${ }^{2}$ É necessário ressalvar, inicialmente, que algumas expressões correntes do vocabulário jurídico-político possuem elevada plurivocidade terminológica, sobretudo, por abrangerem complexas reflexões filosóficas, sociológicas, políticas e jurídicas, que afastam toda pretensão de exaustividade de seus conceitos. Povo, termo caro a qualquer estudo a respeito da democracia, é, conforme análise acurada de Friedrich Müller (2003), uma dessas expressões. A própria democracia é, igualmente, uma noção confusa.
} 
Não obstante as especificidades de cada sistema político e as centenas de classificações alternativas (Cf. GAGNON et al, 2014), pode-se identificar três modelos democráticos principais:

I - A democracia direta, que se caracteriza pelo exercício do poder sem intermediação $\left(\right.$ pelo próprio povo $^{3}$ ) e é, costumeiramente, associada à experiência da Atenas Antiga;

II - A democracia representativa, que ascendeu, contundentemente, a partir do fim do século XVIII e se caracteriza pela seleção popular por meio de sufrágio daqueles que exercerão o poder durante o mandato convencionado;

III - A democracia semidireta, que é proposta como uma alternativa eclética aos outros dois padrões, um modelo misto que concilia elementos de representatividade e de exercício direto do poder, viabilizando a participação popular não-intermediada em determinadas matérias ou ocasiões.

A Constituição Brasileira, ao fazer explícita menção à representatividade e ao exercício direto do poder, opta pelo modelo semidireto (democracia deliberativa), inviabilizando, em tese, a adoção de uma democracia procedimental aos moldes de Schumpeter (1961) e não se esgotando na mera delimitação das "regras do jogo" - em expressão difundida por Norberto Bobbio (1997) - disciplinadoras do processo eleitoral. Parte-se como princípio, portanto, do maximalismo democrático, da necessidade de ampla participação popular.

Embora seja hialino o supramencionado mandamento constitucional, concretizado, com suficiência duvidosa, pelo artigo 14 da própria Constituição e pela lei 9.709/98, entre outros enunciados normativos, é perceptível que a utilização dos institutos de participação popular direta - a exemplo de referendos, plebiscitos e iniciativas populares - é escassa, ocupando a mera representação política espaço desproporcionalmente maior na democracia nacional.

Chega-se, então, ao ponto cuja tentativa de resposta constitui o objetivo nevrálgico deste estudo: como tornar efetivo o exercício da parcela do poder que cabe à população exercer de modo não-intermediado? Questão que pode ser posta, alternativamente, da seguinte forma: como tornar efetiva a utilização dos institutos de participação popular direta?

\footnotetext{
3 Destaca-se que, confirmando a noção cambiante de povo, em Atenas, mulheres e escravos não participavam do processo político, embora superassem numericamente os homens livres atenienses (ROBINSON, 2004).
} 
Problematizações que culminam no alcance das hipóteses relacionadas ao uso da tecnologia em prol da maximização democrática, à realização das condições materiais para uma consciente decisão popular, à extensão do rol constitucional dos institutos de participação popular direta e a sua descentralização.

Para tanto, utilizaremos como referenciais metodológicos a revisão bibliográfica com viés, predominantemente, teórico e a pesquisa documental da produção normativa nacional que perpassa o tema, sem prejuízo a eventuais exemplificações fundamentadas no direito comparado e pontuais menções estatísticas.

Dessarte, será realizada, primeiramente, uma análise crítica da legislação pátria que trata dos institutos de participação popular direta, em seguida, serão apresentados os principais institutos não incorporados pelo ordenamento jurídico brasileiro, em um terceiro momento, tratar-se-á do papel da tecnologia no auxílio do exercício do poder não-intermediado, por fim, serão lançadas as bases do que consideramos ser as principais medidas em prol da busca da efetividade dos institutos de participação popular direta.

Faz-se imperioso, previamente, realizar algumas observações a respeito da terminologia a ser utilizada no decurso do presente trabalho. Por razões estritamente organizatórias, a fim de evitar a dispersão conceitual típica da área, distinguimos:

I - Os mecanismos de participação popular direta (gênero principal), como quaisquer formas de atividade popular não-intermediada no âmbito do poder público;

II - Os mecanismos de participação popular direta informais (espécie de I), como manifestações populares que não possuem sua organização ou seus efeitos definidos juridicamente (tendo, portanto, consequências difusas), a exemplo da tensão das vias institucionais exercida pelos movimentos sociais;

III - Os mecanismos de participação popular direta formais ou institutos de participação popular direta (espécie de I), que são meios juridicamente previstos de ação, deliberação, veto, iniciativa e quaisquer outras formas de exercício do poder sem intermediação de representantes, a exemplo dos referendos;

IV - Os institutos de participação popular direta em sentido estrito (subdivisão de III), que são denominados processos de democracia direta por Rolf Rauschenbach (2014), incluindo, logo, somente os aqueles típicos das democracias diretas: plebiscitos, referendos e iniciativa popular, grosso modo, em oposição ao sentido amplo, que inclui o recall e a própria eleição de representantes. 
A discussão proposta gravita em torno dos institutos de participação popular direta, excluídas de seu âmbito apenas as eleições de representantes, porquanto já são efetivamente realizadas no Brasil (inobstante alguns tópicos problemáticos ${ }^{4}$ que fogem ao nosso escopo e o possível alcance de algumas de nossas conclusões a sua esfera, afinal, pertencem a uma mesma categoria).

\section{INSTITUTOS DE PARTICIPAÇÃO POPUlAR DIRETA PREVISTOS CONSTITUCIONALMENTE}

A Constituição brasileira (BRASIL, 1988) prevê, em seu artigo 14, que "a soberania popular será exercida (...), nos termos da lei, mediante: I - plebiscito; II referendo; III - iniciativa popular", sendo complementada pela lei n. 9.709/98, que exprime conceitos e regulamenta a aplicação dos mecanismos de participação popular direta preceituados constitucionalmente.

\subsection{Referendo e plebiscito}

A palavra referendo advém do latim referendum, gerúndio do verbo refero, que significa "trazer de novo, tornar a levar" (FARIA, 1962, p. 851). O sentido atual do termo data, embora de forma primitiva, do começo do século $\mathrm{XV}$, de onde é, presentemente, o cantão dos Grisões, na Suíça (KOBACH, 1993).

O termo plebiscito, por sua vez deriva do latim plebiscitum, que significa "decreto da plebe" que é utilizado contemporaneamente: consulta direta ao povo, por voto, sobre determinada matéria (OXFORD DICTIONARIES, 2015).

Antes de expor os sentidos de referendo e plebiscito adotado pelo ordenamento jurídico nacional, é necessário observar que a distinção entre as duas modalidades de consulta popular é convencional, ou seja, varia de acordo ao espaçotempo, sendo os vocábulos utilizados de modo intercambiável frequentemente.

\footnotetext{
${ }^{4}$ Sobre uma suposta crise de representatividade, conferir o estudo das transformações do governo representativo, por Bernard Manin (1997).

${ }^{5}$ A respeito do plebiscito na Roma Antiga (onde se originou), assinala John Gilissen (1995, p. 86): "os plebiscitos são actos legislativos obrigando os plebeus e aprovados pela sua assembleia, o concilium plebis: a partir da lex Hortensia (287 a.C.), talvez antes, os plebiscitos são assimilados às leges e obrigam todos os cidadãos".
} 
Na Austrália, por exemplo, o critério de diferenciação é material: os referendos são realizados para aprovar mudanças na Constituição local, enquanto os plebiscitos, também chamados de referendos consultivos, são utilizados para consultar a população quanto a mudanças infraconstitucionais (PARLIAMENTARY EDUCATION OFFICE, 2015).

É perceptível, logo, que referendo e plebiscito são, no ordenamento jurídico brasileiro, institutos análogos, sendo o último nada mais que um tipo específico de referendo $^{6}$ : o referendo ante legem, o que justifica a afirmação de Almino Affonso (1996, p. 15) de que "tudo, a rigor, em sua terminologia, é referendo".

A lei n. 9.709/98 (BRASIL, 1998) estabelece, em seu artigo $2^{\circ}$, que "plebiscito e referendo são consultas formuladas ao povo para que delibere sobre matéria de acentuada relevância, de natureza constitucional, legislativa ou administrativa", utilizando o critério temporal de diferenciação: o plebiscito é uma consulta anterior a ato legislativo ou administrativo, enquanto o referendo é consulta posterior.

O enunciado normativo ainda indica, em seu artigo $3^{\circ}$ (BRASIL, 1998), os prerrequisitos de acionamento dos dois mecanismos: I - material: há de ser uma questão de relevância nacional, de competência do Poder Legislativo ou do Poder Executivo ou deve ter como tema a incorporação, a subdivisão ou o desmembramento de um Estado em outro ou em território federal; II - formal: o plebiscito e o referendo têm como instrumento de convocação o decreto legislativo (prescindindo, por conseguinte, da sanção presidencial), cuja iniciativa deve ser de, pelo menos, um terço dos membros da Câmara dos Deputados ou do Senado Federal.

As estatísticas demonstram a falta de efetividade dos institutos: a nível nacional (excluindo, portanto, os plebiscitos sobre a divisão do Estado do Pará, em 2011 e o referendo sobre o fuso horário vigente no Acre, em 2010), apenas um plebiscito

\footnotetext{
${ }^{6}$ De acordo com Paulo Bonavides (1995), os referendos podem ser classificados de acordo aos seguintes critérios: I - quanto à matéria, em constituintes (referentes a leis constitucionais) ou legislativos (referentes a leis infraconstitucionais); II - quanto aos efeitos, em constitutivos (referentes ao começo da existência de uma norma jurídica) ou ab-rogativos (referentes ao fim da existência de uma norma jurídica); III - quanto à natureza jurídica, em obrigatórios (quando a consulta popular em relação a determinada norma é imposta constitucionalmente) ou facultativos (quando a consulta popular em relação a determinada norma é uma faculdade de órgão público ou de uma parcela do eleitorado); IV - quanto ao tempo, em ante legem (quando a consultar popular antecede o ato legislativo) e post legem (quando a consulta popular é posterior ao ato legislativo); V - quanto às consequências, em vinculante (quando a vontade popular constitui uma imposição ao poder público) e meramente consultivo (quando a vontade popular tem força apenas opinativa); VI - quanto ao motivo, em consultivo (quando o referendo tem como causa a manifestação do parecer popular per se) e arbitral (quando o referendo tem como causa a manifestação do parecer popular para findar divergências entre poderes públicos).
} 
(plebiscito sobre a forma e o sistema de governo, em 1993) - tão-somente por ser fruto de um mandamento constitucional explícito, previsto no art. $2^{\circ}$ do Ato das Disposições Constitucionais Transitórias (BRASIL, 1988), e um referendo (referendo sobre a proibição do comércio de armas de fogo e munições no país, em 2005) foram realizados.

A quase inexistente utilização de ambos os mecanismos está conectada, sobretudo, a duas razões precípuas:

I - À excessiva abertura material da expressão "relevância nacional”, que, verdadeiramente, deixa ao mero alvitre dos representantes a convocação dos plebiscitos ${ }^{7}$, aproximando-se a um referendo facultativo ao poder público e afastando do crivo popular, para nos determos em um singelo exemplo, qualquer decisão concernente à política criminal do país (vide a lei n. 11.343/2006), de relevância nacional inegável;

II - À ausência da possibilidade de convocação popular, através da manifestação de vontade de uma determinada parcela do eleitorado - o denominado referendo facultativo por parte do corpo eleitoral.

A força vinculante dos plebiscitos e referendos é outro importante alvo de controvérsia decorrente da insuficiência de sua regulamentação ${ }^{8}$. É preponderante, doutrinariamente (à medida que a questão ainda não provocou manifestações do Poder Judiciário), a posição favorável à existência de força vinculante, pelo princípio da soberania popular, mas não se pode deixar de condenar tão grave lacuna.

\subsection{Iniciativa popular}

A lei n. 9.709/98 (BRASIL, 1998) define, em seu artigo 13, de acordo com o $\S 2^{\circ}$ do artigo 61 da Constituição Federal (BRASIL, 1988), iniciativa popular como a “apresentação de projeto de lei à Câmara dos Deputados, subscrito por, no mínimo, um por cento do eleitorado nacional, distribuído pelo menos por cinco Estados, com não menos de três décimos por cento dos eleitores de cada um deles", trazendo, ademais, uma ressalva material em seu parágrafo $1^{\mathrm{o}}$ : o referido projeto de lei deve limitar-se a apenas

\footnotetext{
${ }^{7}$ Apenas a decisão a respeito da "incorporação de Estados entre si, subdivisão ou desmembramento para se anexarem a outros, ou formarem novos Estados ou Territórios Federais", de acordo com o art. $4^{\mathrm{o}}$ da lei n. 9.709/98 (BRASIL, 1998), deverão ser, expressamente, submetidas à vontade popular - embora não definitivamente.

8 Trata-se de uma omissão legislativa parcial, porquanto os plebiscitos sobre incorporação, desmembramento ou subdivisão de Estado carecem de força vinculante, à medida que, em caso de aprovação popular, a matéria ainda deve ser remetida ao crivo do Congresso Nacional.
} 
um assunto 9 . Há, igualmente, salutar previsão constitucional (BRASIL, 1988) de ampliação da iniciativa popular às esferas estadual e municipal, de acordo com os artigos $27, \S 4^{\circ}$ e 29, XIII.

Pode-se identificar, portanto, uma limitação de caráter quantitativo - “um por cento do eleitorado nacional, (...) com não menos de três décimos por cento dos eleitores de cada um deles" - e outra de caráter geográfico, visando a uma melhor representação espacial - "distribuído pelo menos por cinco Estados".

Nítido é que inexiste força vinculante na iniciativa popular, consoante Angelo Braga Netto Rodrigues de Melo (2013, p.1):

\begin{abstract}
Quanto à iniciativa popular legislativa, é de bom alvitre lembrar-se que esta apenas altera o momento inicial do processo legislativo, quer dizer, ela apenas provoca uma alternância na legitimidade ordinária para a propositura dos projetos de lei. Dessa forma, seria uma contradição em termos torná-la obrigatória, pois isso implicaria afirmar que projeto proposto é projeto aceito, passando-se por cima da deliberação, pelo que ela é, sempre, consultiva.
\end{abstract}

Quatro projetos de iniciativa popular foram convertidos em lei sob os moldes da Constituição de 1988: a lei n. 8.730/94 (BRASIL, 1994), que caracterizou o homicídio praticado "em atividade típica de grupo de extermínio" como crime hediondo; a lei n. 9.840/99 (BRASIL, 1999), que tornou a compra de votos crime passível de cassação; a lei n. 11.124 (BRASIL, 2005), de 2005, que criou o Fundo Nacional de Habitação de Interesse Nacional e a Lei Complementar n. 135 (BRASIL, 2010), conhecida como "Lei da Ficha Limpa".

Cabe ressalvar, porém, de acordo com a crítica de Pedro Lenza (2012), que apenas a iniciativa da lei n. 11.124/2005 foi verdadeiramente popular: embora cerca de um milhão e trezentas mil pessoas tenham assinado o projeto de iniciativa popular da lei n. 8.730/94, o projeto foi encaminhado pelo Presidente da República; no caso da lei n. 9.840/99, mais de novecentas mil assinaturas haviam sido colhidas, porém o projeto foi subscrito por sessenta parlamentares e o projeto da "Lei da Ficha Limpa", conquanto tenha contado com expressivo apoio popular, foi originário do Poder Executivo.

A limitada utilização da iniciativa popular é explicada pelos empecilhos impostos, em lei, para a sua deflagração, que, não obstante necessários para evitar que um sem-número de projetos sejam apresentados à Câmara dos Deputados, impossibilitam

\footnotetext{
${ }^{9}$ O parágrafo segundo do mesmo dispositivo traz, também, uma observação fundamental: não se poderá rejeitar projeto de lei de iniciativa popular por vício de forma (técnica ou redação legislativas).
} 
a plena realização do preceito constitucional, à medida que, segundo Rolf Rauschenbach (2014), apenas cinco projetos de lei de iniciativa popular foram apresentados ao Congresso Nacional.

Consideramos, portanto, salutar o teor da PEC 286/2013, que promove a ampliação do âmbito da iniciativa popular às emendas constitucionais - cabe observar que José Afonso da Silva (2005) já as considera permitidas - e diminui o percentual de assinaturas do eleitorado nacional em meio por cento para as leis ordinárias, com não menos de um décimo por cento dos eleitores de, pelo menos, cinco Estados diferentes, facilitando, dessarte, o árduo processo de iniciativa popular; além do projeto de lei n. 4.764/2009, que objetiva a regulamentação do uso da internet na iniciativa popular (assinaturas digitais), entre outras propostas no mesmo diapasão.

A "lacuna das assinaturas", inclusive, extrapola a ausência da permissão do uso de assinaturas digitais, conforme Hélcio Ribeiro (2007, pp. 28-29):

\begin{abstract}
Duas últimas questões devem ser levantas em relação às assinaturas: o controle da autenticidade e os prazos para coleta das mesmas. Não há previsão constitucional neste sentido. Entretanto, a legislação regulamentadora deveria ter tratado destes temas como forma de garantir a idoneidade do processo. A lei n. 9709 nada estabeleceu a respeito. (...) Em outros países esse controle é feito pelos próprios órgãos do Estado. Na Itália cabe ao Poder Judiciário conferir a autenticidade das assinaturas e nos Estados Unidos à Secretaria de Estado. Neste país as assinaturas são conferidas por amostragem e, em casos de dúvida, submete-se toda a lista a uma averiguação rigorosa, havendo casos de propostas que tiveram milhares de assinaturas anuladas.
\end{abstract}

\title{
3 INSTITUTOS DE PARTICIPAÇÃO POPULAR DIRETA NÃO PREVISTOS CONSTITUCIONALMENTE
}

Os principais mecanismos de participação popular direta que não foram recepcionados pela Constituição Federal de 1988 são: o recall ou direito de revogação do mandato político, em sua forma genérica ou nos moldes do abberufungsrecht, e o veto popular.

\subsection{Mandato imperativo, recall e abberufungsrecht}

Antes de discorrer sobre o recall, faz-se mister ponderar sobre o mandato imperativo, que, conquanto não seja um mecanismo de participação popular direta, guarda similitudes relevantes com o recall: o mandato imperativo, forma habitual de 
representação durante a Idade Média e a Revolução Francesa, apesar de pouco praticado atualmente (AZAMBUJA, 2006), é caracterizado pela vinculação do mandato do representante popular às instruções de seu eleitorado ou de seu partido, sob pena de destituição do cargo político.

Por sua vez, o recall (revocação, revogação, em tradução livre), que se difundiu nos Estados Unidos no começo do século XX, onde continua a ser utilizado, pode ser definido como o direito à revogação do mandato político (embora, em sentido estrito) ou "um meio ou procedimento através do qual o eleitorado pode revogar a investidura (eleitoral ou administrativa) de um agente público ou rever uma decisão judicial” (SANTANA, 2004, pp. 8-9).

Há, outrossim, o instituto análogo, de origem helvética, do abberufungsrecht (direito de revogação, em tradução livre), que é uma forma específica de recall: o direito de revogar os mandatos de todos os membros de uma assembleia ou parlamento (BONAVIDES, 1995), i.e., a aplicação coletiva do recall.

$\mathrm{O}$ recall, em todas as suas formas, desempenha fundamental papel na democracia semidireta ao criar um artifício jurídico, posto que mais brando que o mandat impératif, que conceda aos eleitores algum controle sobre a atividade dos representantes durante os seus mandatos.

Entre os críticos do recall e/ou do mandato imperativo estão Norberto Bobbio (1987), que observa neste a evanescência da distinção entre representação com mandato e representação sem mandato, e Bernard Manin (1997), que vê em ambas as práticas a privação de qualquer forma de independência dos representantes - um dos princípios basilares do governo representativo, segundo o próprio cientista político francês.

Durante a Assembleia Nacional Constituinte que elaborou a Constituição de 1988, foi proposto o voto destituinte, uma espécie de recall que necessitaria de ratificação do Poder Legislativo (ÁVILA, 2009). A inexistência de distanciamento entre a Assembleia e a política ordinária e a confusão quanto à essência do instituto explicam o rechaço da proposta.

Embora não faça parte do ordenamento jurídico nacional, pode-se identificar, de acordo com Alexander Santana (2004), a vasta utilização do direito à revogação do mandato em outros países: além dos mencionados Estados Unidos (recall) e Suíça (abberufungsrecht), o instituto é utilizado, por exemplo, na Venezuela (referendo revocatorio), na Federação Russa (embora pouco utilizado), na Colômbia (aos moldes de 
um mandato imperativo que vincula promessas) e na Argentina (revocatoria del mandato).

Em semelhante diapasão a Caio Márcio de Brito Ávila (2009), pode-se considerar o direito à destituição de uma autoridade pública (especialmente, os representantes políticos) uma alternativa para a ampliação do modesto rol de institutos de participação popular direta constitucionais, apresentando-se mais viável, inicialmente, em âmbito municipal e, acrescentamos, apenas para vereadores e prefeitos, como no abberufungsrecht cantonal suíço.

De tal modo, permite-se, mediante devida regulamentação (que, pode, como na Colômbia, apenas vincular o agente público às suas próprias declarações ou “promessas"), que os cidadãos (diferenciando o mecanismo, portanto, do impeachment $\mathrm{e}$ afins) possam, por iniciativa própria e a qualquer tempo, manifestar insatisfação com os agentes públicos, com a previsão de efetivas consequências legais predeterminadas (diferenciando o instituto, portanto, dos mecanismos de participação direta informais).

\subsection{Veto popular}

Denomina-se veto popular o mecanismo através do qual os eleitores podem impedir que um enunciado normativo aprovado pela autoridade pública competente entre em vigência. $\mathrm{O}$ silêncio popular, à vista disso, possuiria valor de aquiescência com a norma jurídica que está prestes a viger (BONAVIDES, 1995). Na lição de Dalmo Dallari (2011, p. 155):

O veto popular é um instituto que guarda certa semelhança com o referendum, sendo mesmo denominado por autores norte-americanos de mandatory referendum. Pelo veto popular, dá-se aos eleitores, após a aprovação de um projeto pelo Legislativo, um prazo, geralmente de sessenta a noventa dias, para que requeiram a aprovação popular. A lei não entra em vigor antes de decorrido esse prazo e, desde que haja solicitação por um certo número de eleitores, ela continuará suspensa até as próximas eleições, quando então o eleitorado decidirá se ela deve ser posta em vigor ou não (grifos do autor).

O veto popular seria mais um instituto em prol da autonomia decisória popular: funcionaria como um referendo facultativo a ser convocado por uma parcela da população para deliberar a respeito de um enunciado normativo (defendemos a criação de uma barreira material bem definida, que limitaria o instituto às propostas de emenda 
constitucional que tratem de matérias previstas no rol das cláusulas pétreas ${ }^{10}$, e.g.), podendo ser, consequentemente, implementado no Brasil por mera edição da lei n. 9.709/98, sem a necessidade de emenda constitucional.

Embora jamais tenham sido aplicados de modo sistemático no Brasil, o recall e o veto popular são alvos constantes de reivindicação social e de propostas legislativas. Desde a promulgação da Constituição de 1988, duas Propostas de Emenda à Constituição tentaram incluir, na esfera dos mecanismos de participação popular direta previstos constitucionalmente, institutos semelhantes ao recall, ao abberufungsrecht e ao veto popular: a PEC 80, de 2003 e a PEC 73, de 2005, porém não obtiveram êxito até o momento.

\section{A TECNOLOGIA EM PROL DOS INSTITUTOS DE PARTICIPAÇÃO POPULAR DIRETA}

A principal justificativa para a prática de uma democracia predominantemente representativa reside no que cunhamos de dogma da inviabilidade da democracia direta: as grandes populações, dispersas em grandes porções territoriais, a expansão do direito à participação (eliminando critérios censitários, étnicos, de sexo, entre outros), os altos custos e a complexidade crescente da sociedade, exigindo do poder público maior atividade em um menor período de tempo ${ }^{11}$, inviabilizariam a reunião frequente em assembleia e o exercício pleno do poder pelo povo.

Além do dogma da inviabilidade da democracia direta, é, costumeiramente, utilizado o argumento da incapacidade dos "cidadãos comuns" para justificar uma democracia minimalista ou meramente representativa. Montesquieu (1996, p. 171), por exemplo, mencionava que "havia um grande vício na maioria das antigas repúblicas: é que o povo tinha o direito de tomar decisões ativas, (...) coisa da qual ele é incapaz. Ele só deve participar do governo para escolher seus representantes (...)"12.

\footnotetext{
${ }^{10}$ Sem, obviamente, tender a aboli-las, conforme a previsão do art. $60, \S 4^{\circ}$, da Constituição Federal (BRASIL, 1988).

11 Sobre o tema, é proveitoso mencionar a expressão "dromocracia" (dromos: corrida; kratos: poder/governo), cunhada por Paul Virilio e citada por Willis Santiago Guerra Filho (1997), para definir o panorama atual.

${ }^{12}$ Sobre uma suposta ineficiência popular, Darcy Azambuja (2006, p. 223 apud BARTHELEMY; DUEZ, 1933, p. 84) assinala que, no cantão de Uri, na Suíça, em 1911, "várias sessões foram dedicadas à questão de permitir dançar aos domingos, e em uma única sessão foi aprovado um Código Civil completo".
} 
Tal argumento é rejeitado à medida que a mescla de representação política com institutos de participação popular direta é um mandamento constitucional e que, na esteira de Rolf Rauschenbach (2014, p. 219), há uma contradição em "atribuir ao cidadão a competência de saber eleger o seu representante e ao mesmo tempo a incompetência de participar em processos de democracia direta".

Contudo, o mesmo aumento de complexidade social que impossibilitou a expansão da democracia direta é, com o suporte de avanços tecnológicos, uma alternativa, ainda que não para seu retorno, para a utilização mais consistente dos mecanismos de participação popular sem intermediação ${ }^{13}$.

Sobre as possibilidades contidas na "democracia digital", comenta Dalmo Dallari (2011, p. 153):

No momento em que os mais avançados recursos técnicos para captação e transmissão de opiniões, como terminais de computadores, forem utilizados para fins políticos será possível a participação direta do povo, mesmo nos grandes Estados. Mas para isso será necessário superar as resistências dos políticos profissionais, que preferem manter o povo dependente de representantes.

Exemplo de aplicação da tecnologia em prol da participação popular direta e da resistência dos "entes políticos ordinários" é a vanguardista experiência islandesa, iniciada em 2009, na elaboração de uma nova constituição com auxílio de mecanismos de crowdsourcing, que permitiram que a população islandesa participasse da elaboração da Constituição com críticas, sugestões e votações em um website projetado para tal fim.

Segundo relato de Thorvaldur Gylfason (2012), o processo constitucional também incluiria, como etapa inicial ${ }^{14}$, a convocação de uma Assembleia Nacional formada por mais de mil cidadãos islandeses escolhidos aleatoriamente (embora com

13 São muitas, outrossim, as propostas que pugnam por mudanças substantivas, na democracia contemporânea, instrumentalizadas por meios eletrônicos, como: I - A democracia delegativa de Bryan Ford (2002) - não confundir com o fenômeno de nome idêntico descrito por Guillermo O’Donnell (1991) - que consiste em atribuir a cada eleitor a capacidade de participar do exercício do poder ativa ou passivamente, caso deseje participar de modo passivo, delegaria seu poder de voto, eletronicamente, para um representante (participante ativo). O número de representantes seria ilimitado, possuindo cada um o poder de votar por si mesmo e por quem o delegar. Cada cidadão eleitoralmente ativo seria, dessarte, representado, ao contrário do que acontece na democracia representativa tradicional, onde um grande contingente populacional não logra eleger seus candidatos. O Partido Pirata alemão e o antigo partido sueco Demoex (que obteve êxito em eleições locais, utilizando, inclusive, o sorteio para escolher seus candidatos) são os mais notórios partidos políticos que defendem a democracia delegativa (FORD, 2014); II - A "democracia líquida", preconizada pelo islandês Smári McCarthy, cofundador do partido Pirata islandês, que também propõe a delegação de votos por meio eletrônico, além de propor, também, a utilização de mecanismos de crowdsourcing (MCCARTHY, 2015).

${ }^{14}$ As outras duas etapas foram: indicação de sete membros de um Comitê Constitucional, que teve a função de compor um relatório com informações, análises e ideias a respeito da nova Constituição e realização de uma eleição para a Assembleia Constitucional, composta por 25 membros, para concluir o processo. Cabe observar que o método eleitoral utilizado foi o single-transferable-vote (STV). 
garantias de representação proporcional por idade e sexo, por exemplo) para preparar um esboço da Constituição - permitindo uma analogia ao modelo de sorteio praticado na Atenas Antiga, berço da democracia direta.

Apesar do expressivo apoio popular à proposta ${ }^{15}$, a Suprema Corte Islandesa interviu no processo e declarou nula a eleição para a Assembleia Constitucional (transformada, pelo Parlamento local, posteriormente, em um Conselho Constitucional com as mesmas atribuições e 24 dos 25 membros da Assembleia) e o Parlamento (eleito em um momento posterior - 2013) suspendeu as votações da nova Constituição, evidenciando que os interesses populares nem sempre (ou quase nunca) correspondem aos interesses dos "políticos profissionais" mencionados por Dalmo Dallari.

O exercício da democracia por meios eletrônicos permitiria ao cidadão maior acesso ao processo decisório público sem a necessidade de grandes mobilizações financeiras ou temporais. Wilson Gomes (2005, pp. 218-219) aponta os seguintes graus de e-democracy:

O grau mais elementar é aquele representado pelo acesso do cidadão aos serviços públicos através da rede (os serviços de Estado entregues em domicílio ou a cidadania delivery). (...) O segundo grau é constituído por um Estado que consulta os cidadãos pela rede para averiguar a sua opinião a respeito de temas da agenda pública e até, eventualmente, para a formação da agenda pública. (...) O terceiro grau de democracia digital é representado por um Estado com tal volume e intensidade na sua prestação de informação e prestação de contas que, de algum modo, adquire um alto nível de transparência para o cidadão comum. (...) O quinto grau, evidentemente, é representado pelos modelos de democracia direta, onde a esfera política profissional se extinguiria porque o público mesmo controlaria a decisão política válida e legítima no interior do Estado. (...). Uma democracia digital de quarto grau corresponderia a determinados modelos de democracia deliberativa. À diferença da democracia de quinto grau, a democracia deliberativa combina o modelo de democracia participativa com o modelo de democracia representativa.

Além dos benefícios em esferas informais de participação popular, a exemplo da criação de áreas de debate virtual e maior acesso à informação - formalizado pela lei n. 12.527/2011 (BRASIL, 2011), que menciona o acesso virtual à informação em diversos dispositivos - pode-se acrescentar um possível melhoramento dos institutos de participação popular direta já existentes através, por exemplo, da utilização das já

\footnotetext{
${ }^{15}$ De acordo a Smári McCarthy (2014), foi realizado um referendo a respeito do projeto de Constituição baseado nas recomendações do Conselho Constitucional, que resultou na aprovação do projeto com $73 \%$ dos votos.
} 
mencionadas assinaturas digitais ${ }^{16}$, que tornariam desnecessário o deslocamento físico do cidadão para manifestar-se, facilitando, sobretudo, as iniciativas populares.

No Brasil, além do supramencionado projeto de lei n. 4.764/2009, há a Comissão de Legislação Participativa da Câmara dos Deputados e o portal e-Democracia, desenvolvido pela mesma Câmara, que, apesar de atuarem timidamente, visam a, por intermédio da internet, aproximar a sociedade civil do processo decisório político.

A democracia eletrônica tem seu avanço impedido pela falta de acesso universal aos dispositivos que permitem o seu uso ${ }^{17}$ e pela relativa falta de segurança, à medida que os meios de identificação digital ainda não são completamente seguros e exigem um aparato tecnológico específico e mais custoso.

De tal forma, embora seja plausível pugnar por uma "democracia eletrônica de quarto grau", com amplo confronto de ideias em arenas virtuais, com a proposição de temas para a discussão pública, com transparência e publicidade facilitadas e inserindo mecanismos eletrônicos de instrumentalização subsidiária dos institutos de participação popular direta, é infactível, atualmente, planejar uma democracia virtual de quinto grau no Brasil.

É imperioso advertir que mesmo a utilização massiva de mecanismos de participação popular direta não garante o sucesso do sistema democrático ${ }^{18}$. A autogestão não soluciona, por si só, os problemas dos consensos construídos mediante opressão de minorias, da falta de vontade de exercitar o poder de parte da população ou da participação maculada por manipulação ou falta de informação.

\section{CONSIDERAÇÕES FINAIS}

É perceptível que, no panorama político-constitucional contemporâneo, há uma tendência a eleger o povo como a fonte suprema do poder público, logo, a

\footnotetext{
${ }^{16}$ A possibilidade de equiparação da assinatura digital à assinatura manuscrita é controversa, inclusive, em outros âmbitos, como no comércio eletrônico (Cf. LINS, 2005).

17 Segundo relatório de uma agência da ONU, União Internacional de Telecomunicações (INTERNATIONAL TELECOMMUNICATION UNIT, 2015), apenas $57,6 \%$ da população brasileira possui acesso à internet, em contraste com o expressivo número de $98,2 \%$ da Islândia.

${ }^{18}$ Mesmo o avançado sistema de democracia semidireta suíço não é isento de críticas. Uwe Serdült (2007) elenca as seguintes falhas do modelo helvético: a falta de regulamentação do financiamento (especialmente, o partidário) das campanhas dos referendos; o baixo nível de comparecimento popular - de acordo ao Federal Statiscal Office da Suíça (2015), a participação em referendos nacionais desde a década de 1990 flutua, em média, entre 40 e $50 \%$ - e a utilização capciosa dos institutos de democracia direta para interesses organizados, a exemplo de partidos políticos e grupos de interesse.
} 
democracia aparece como o regime de governo a permitir a concretização do exercício da soberania nacional popular.

Surge, então, o desafio de estabelecer como o poder será exercido: a forma direta é, naturalmente, a mais cara à essência do sistema democrático, mas se torna inviável nas complexas sociedades integradas globalmente, cedendo lugar a modelos completamente representativos ou a modelos mistos, onde o povo tem a oportunidade de se manifestar diretamente sobre temas de maior relevância - a denominada democracia deliberativa.

O Brasil, apesar de adotar o modelo eclético formalmente, sofre com a escassez da utilização dos mecanismos de participação popular direta, que, ainda, limitam, demasiadamente, a atuação do povo, que, por iniciativa própria, não pode convocar referendos ou plebiscitos nem revisar a Constituição Federal, além de não possuir direito à revogação de mandato político e só ser, obrigatoriamente, consultado em caso de incorporação, subdivisão ou desmembramento de um Estado, ocasião em que seu parecer afirmativo sequer é vinculativo.

Pode, dessarte, o Estado brasileiro ser definido como uma democracia semidireta formal e uma democracia representativa material. A aproximação à previsão constitucional de participação popular direta conjunta à atividade de representantes passa:

I - Pela facilitação do uso dos institutos de participação popular direta já previstos constitucionalmente: utilização de assinatura digital e diminuição do número mínimo de signatários na iniciativa popular, ampliação do número de hipóteses onde a convocação de referendos e plebiscitos é obrigatória (não fosse a verdadeira profusão de emendas constitucionais, poderia se pensar em exigir convocação de referendo sempre que houvesse modificação no texto da Lei Maior, como na Suíça - ainda assim, é possível delimitar um núcleo constitucional essencial que dependa da aprovação popular para ser modificado) e previsão de convocação popular de tais formas de consulta;

II - Pela expansão do rol constitucional de mecanismos: inclusão do direito de revogação do mandato político em âmbito municipal, do veto popular (como instrumento de controle negativo), que sequer necessitaria de emenda à Constituição para ser viabilizado e de outras alternativas em âmbito local, como o orçamento participativo, cuja pioneira experiência em Porto Alegre foi bem relatada por Boaventura de Sousa Santos (2002).

III - Por um maior acesso às informações relacionadas à atuação do Poder Público (transparência e publicidade), a fim de que a população possa exercer mais 
firmemente seu papel fiscalizador e fazer suas opções políticas conscientemente (mesmo que de forma ainda heurística);

IV - Pelo reconhecimento formal da força vinculante das decisões populares como regra.

Despontam, igualmente, como alternativas de sistemas semidiretos as propostas de democracia líquida, delegativa e eletrônica - sobretudo, a última, no nomeado "quarto grau de democracia virtual" - além do crowdsourcing, que mitigariam o dogma da inviabilidade da democracia direta, introduzindo o progresso tecnológico como alavanca para uma mudança de paradigma no exercício do poder político: do paradigma do cidadão espectador para o paradigma do cidadão ator.

A importância da aplicação e da ampliação dos institutos de participação popular direta tem respaldo não somente no cumprimento de um mandamento constitucional, mas na concretização do sistema democrático em si, para que o povo tenha uma esfera mínima fundamental de controle direto do poder.

Apesar de fundamental, o exercício do poder pelo povo não é a panaceia que libertará o sistema democrático dos fantasmas da delegação de poder - na conotação dada por Guillermo O’Donnell (1991), da opressão da maioria (ou da minoria), da corrupção e da opinião pública impulsiva e volátil.

O povo não é, per se, incapaz de tomar decisões políticas acertadas, mas não é um ente superior incapaz de falhas ou de ser manipulado, logo, a problemática da boa governança não é resolvida tão-somente no âmbito de quem governa: as garantias de pleno acesso à informação e de liberdade de expressão (em suas dimensões positiva e negativa) são, igualmente, essenciais para que quem governe possa exercer seu papel eficaz e legitimamente. Pode-se mencionar como controvérsia fulcral, também, a colossal querela que envolve o "como governar", que transborda o âmbito da escolha dos governantes e foge ao escopo do presente trabalho.

A democracia ineducada, seja direta, semidireta ou representativa, seja construção meramente do formalismo jurídico ou alicerçada, de modo material, no âmago da estrutura social, degenera-se, facilmente, em alguma das diversas formas de ditadura da ignorância. O fomento dos institutos de participação popular não é, ressalte-se, cura miraculosa de todas as mazelas políticas, mas um primeiro passo sólido em direção a uma real democracia deliberativa. 


\title{
THE EFECTIVATION OF THE INSTITUTES OF DIRECT POPULAR PARTICIPATION IN BRAZIL
}

\author{
Gabriel Santos Rios
}

\begin{abstract}
The present paper aims to propound and analyze possible alternatives for the effectuation of the institutes of direct popular participation in Brazil, adopting as a starting point the contrast between the constitutional command in favor of a semidirect democracy (democratic maximalism) and the scarce utilization of referendums, plebiscites and popular initiatives. For this purpose, there will be a bibliographic revision mixed with a documental research, allowing a critical analysis of the formal mechanisms of nonintermediated popular participation laid down constitutionally, the main institutes not laid down constitutionally and the role that can be played by technology in the concretization of a deliberative model of democracy, including the mitigation of the "dogma of the infeasibility of direct democracy". It is concluded with the suggestion of the foundations of an effective participative democracy in Brazil, including the extension of the list of institutes of direct popular participation (nationally and locally), the facilitation of their use (by, e.g., eletronic means), the possibility for people to summon referendums and plebiscites and the consolidation of the binding force of the popular decisions, also pointing that the broad utilization of instruments that allow the people to exercise the political power only is not enough to build a truly democratic State, despite being a very solid initial step.
\end{abstract}

Keywords: Semidirect democracy. Direct popular participation. Electronic democracy.

\section{REFERÊNCIAS}

AFFONSO, Almino. Democracia participativa: plebiscito, referendo e iniciativa popular. Revista de Informação Legislativa, v. 33, n. 132, p. 11-27, 1996.

ÁVILA, Caio Márcio de Brito. Recall - a revogação do mandato político pelos eleitores: uma proposta para o sistema jurídico brasileiro. São Paulo: USP, 2009.

AZAMBUJA, Darcy. Teoria Geral do Estado. Ed. 44. Brasil: Globo, 2006.

BARTHELEMY, Joseph; DUEZ, Paul. Traité de Droit constitutionnel. Paris: Dalloz, 1933.

BOBBIO, Norberto. Estado, Governo, Sociedade: para uma teoria geral da política. Ed. 12. Rio de Janeiro: Paz e Terra, 1987. 
BOBBIO, Norberto. O Futuro da Democracia: Uma Defesa das Regras do Jogo. Ed. 6. Rio de Janeiro: Paz e Terra, 1997.

BONAVIDES, Paulo. Ciência Política. Ed. 10. São Paulo: Malheiros Editores, 1995.

BRASIL. Constituição da República Federativa do Brasil, de 05 de outubro de 1988. Diário Oficial da União, Brasília, 1988. Disponível em: $<$ http://www.planalto.gov.br/ccivil_03/constituicao/constituicao.htm>. Acesso em: 05/08/2015.

BRASIL. Lei n. 8.930, de 6 de setembro de 1994. Dá nova redação ao art. $1^{\circ}$ da Lei n. 8.072, de 25 de julho de 1990, que dispõe sobre os crimes hediondos, nos termos do art. $5^{\circ}$, inciso XLIII, da Constituição Federal, e determina outras providências. Diário Oficial da União, Brasília, $1994 . \quad$ Disponível em: $<$ http://www.planalto.gov.br/CCivil_03/Leis/L8930.htm>. Acesso em: 08/08/2015.

BRASIL. Lei n. 9.709, de 18 de novembro de 1998. Regulamenta a execução do disposto nos incisos I, II e III do art. 14 da Constituição Federal. Diário Oficial da União, Brasília, 1998. Disponível em: <http://www.planalto.gov.br/ccivil_03/leis/19709.htm>. Acesso em: 05/08/2015.

BRASIL. Lei n. 9.840, de 28 de setembro de 1999. Altera dispositivos da Lei n. 9.504, de 30 de setembro de 1997, e da Lei no 4.737, de 15 de julho de 1965 - Código Eleitoral. Diário Oficial da União, Brasília, 1999. Disponível em: $<$ http://www.planalto.gov.br/ccivil_03/leis/L9840.htm>. Acesso em: 08/08/2015.

BRASIL. Lei n. 11.124, de 16 de junho de 2005. Dispõe sobre o Sistema Nacional de Habitação de Interesse Social - SNHIS, cria o Fundo Nacional de Habitação de Interesse Social - FNHIS e institui o Conselho Gestor do FNHIS. Diário Oficial da União, Brasília, 2005. Disponível em: <http://www.planalto.gov.br/ccivil_03/_ato20042006/2005/lei/111124.htm>. Acesso em: 08/08/2015.

BRASIL. Lei Complementar n. 135, de 4 de junho de 2010. Altera a Lei Complementar n. 64, de 18 de maio de 1990, que estabelece, de acordo com o $\S 9^{\circ}$ do art. 14 da Constituição Federal, casos de inelegibilidade, prazos de cessação e determina outras providências, para incluir hipóteses de inelegibilidade que visam a proteger a probidade administrativa e a moralidade no exercício do mandato. Diário Oficial da União, Brasília, 2010. Disponível em: <http://www.planalto.gov.br/ccivil_03/leis/LCP/Lcp135.htm>. Acesso em: 08/08/2015.

BRASIL. Lei n. 12.527, de 18 de novembro de 2011. Regula o acesso a informações previsto no inciso XXXIII do art. 5o, no inciso II do $\S 30$ do art. 37 e no $\S 20$ do art. 216 da Constituição Federal; altera a Lei no 8.112, de 11 de dezembro de 1990; revoga a Lei no 11.111 , de 5 de maio de 2005, e dispositivos da Lei no 8.159, de 8 de janeiro de 1991; e dá outras providências. Diário Oficial da União, Brasília, 2011. Disponível em: $<$ http://www.planalto.gov.br/ccivil_03/_ato2011-2014/2011/lei/112527.htm>. Acesso em: $24 / 01 / 2016$.

DALLARI, Dalmo. Elementos de Teoria Geral do Estado. Ed. 30. São Paulo: Saraiva, 2011. 
FARIA, Ernesto (org.). Dicionário escolar latino-português. Ed. 3. Rio de Janeiro: Campanha Nacional de Material de Ensino, 1962.

FEDERAL STATISCAL OFFICE. Statistical Data on Switzerland 2015. Suíça: Section Dissemination and Publications, 2015.

FILHO, Willis Santiago Guerra. Autopoiese do Direito na Sociedade Pós-Moderna: introdução a uma teoria social sistêmica. Porto Alegre: Livraria do Advogado, 1997.

FORD, Bryan. Delegative democracy. Bryan Ford's Home Page, Estados Unidos, 15 de maio de 2002. Disponível em: <http://www.brynosaurus.com/deleg/deleg.pdf $>$. Acesso em: $11 / 08 / 2015$.

FORD, Bryan. Delegative democracy revisited. Bryan Ford's Home Page, Estados Unidos, 16 de novembro de 2014. Disponível em: $<$ http://bford.github.io/2014/11/16/deleg.html>. Acesso em: 11/08/2015.

GAGNON, Jean-Paul et al. Democratic Theories Database: Five Hundred and Seven Theories of Democracy. Working Paper \#1, Australian Catholic University, Research Node in the Sydney Democracy Network, novembro de 2014. Disponível em: < http://sydneydemocracynetwork.org/wp-content/uploads/2014/11/Democratic-TheoriesDatabase.pdf $>$. Acesso em: 24/01/2016.

GILISSEN, John. Introdução histórica ao Direito. Ed. 2. Lisboa: Fundação Calouste Gulbenkian, 1995.

GOMES, Wilson. A democracia digital e o problema da participação civil na decisão política. Revista Fronteiras - Estudos Midiáticos, São Leopoldo, v. 7, n. 3, Unisinos, setembro/dezembro de 2005.

GYLFASON, Thorvaldur. From Collapse to Constitution: The Case of Iceland. Center for Economic Studies and Ifo Institute, CESifo Working Paper Series No. 3770, Islândia, junho de 2012.

INTERNATIONAL TELECOMMUNICATION UNIT. The State of Broadband 2015. Suíça: ITU and UNESCO, 2015.

KOBACH, Kris. The referendum: direct democracy in Switzerland. Estados Unidos: Dartmouth, 1993.

LENZA, Pedro. Direito constitucional esquematizado. Ed. 16. São Paulo: Saraiva, 2012.

LINS, Bernardo Felipe Estellita. Comércio eletrônico, assinatura e certificação digital. Câmara dos Deputados: Brasília, 2005. Disponível em: $<$ http://www2.camara.leg.br/documentos-e-pesquisa/publicacoes/estnottec/areas-daconle/tema4/2005_2685.pdf>. Acesso em: 23/01/2016.

MANIN, Bernard. The principles of representative government. Inglaterra: Cambridge University Press, 1997. 
MCCARTHY, Smári. Utopia Lost: Lessons From Iceland. The London School of Economics and Political Science, Londres, 2014. Disponível em: < http://blogs.lse.ac.uk/constitutionuk/2014/01/21/utopia-lost-lessons-from-iceland/>.

Acesso em: 15/11/2015.

MCCARTHY, Smári. Projects. Smári McCarthy Home Page, Islândia, 2015. Disponível em: <http://smarimccarthy.is/projects/>. Acesso em: 15/11/2015.

MELO, Angelo Braga Netto Rodrigues de. Conteúdo dos institutos do plebiscito, referendo e iniciativa popular. Revista Jus Navigandi, Teresina, ano 18, n. 3780, 6 nov. 2013. Disponível em: <http://jus.com.br/artigos/25704>. Acesso em: 6 ago. 2015.

MONTESQUIEU, Charles. Do espírito das leis. Ed. 2. São Paulo: Martins Fontes, 1996.

MÜLLER, Friedrich. Quem é o povo? A questão fundamental da democracia. Ed. 3. São Paulo: Max Limonad, 2003.

O’DONNELL, Guillermo. Democracia Delegativa? Novos Estudos CEBRAP, n. 31, outubro de 1991.

OXFORD DICTIONARIES. Plebiscite (England - UK). Reino Unido. Disponível em: $<$ http://www.oxforddictionaries.com/definition/english/plebiscite $>$. Acesso em: 05/08/2015.

PARLIAMENTARY EDUCATION OFFICE. Referendums and Plebiscites. Austrália. Disponível em: $\quad<$ http://www.peo.gov.au/learning/fact-sheets/referendums-andplebiscites.html>. Acesso em: 05/08/2015.

RAUSCHENBACH, Rolf. Processos de democracia direta: sim ou não? Os argumentos clássicos à luz da teoria e da prática. Revista de Sociologia e Política, Paraná, v. 22, n. 49, UFP, mar. 2014, pp. 205-230.

RIBEIRO, Hélcio. A iniciativa popular como instrumento da democracia participativa. Universidade Presbiteriana Mackenzie, Faculdade de Direito, 2007. Disponível em: $<$ http://www.mackenzie.br/fileadmin/Graduacao/FDir/Artigos/helcioribeiro.pdf $>$. Acesso em: 22/01/2016.

ROBINSON, Eric. Ancient Greek Democracy: readings and sources. Reino Unido: Blackwell Publishing, 2004.

SANTANA, Alexander. O direito de revogação do mandato político representativo. Curitiba: edição do autor, 2004.

SANTOS, Boaventura de Sousa (org.). Democratizar a democracia: os caminhos da democracia participativa. Rio de Janeiro: Civilização Brasileira, 2002.

SCHUMPETER, Joseph. Capitalismo, Socialismo e Democracia. Rio de Janeiro: Fundo de Cultura, 1961. 
SERDÜLT, Uwe. Direct Democracy in Switzerland and its Discontents. In: CONFERENCIA INTERNACIONAL DE DEMOCRACIA DIRECTA EN AMÉRICA LATINA, 14/15 de março de 2007, Buenos Aires, Argentina. Disponível em: $<$ http://www.whatisdemocracy.net/wddm/maillist/Direct_Democracy_in_Switzerland.p $\mathrm{df}>$. Acesso em: 10/08/2015.

SILVA, José Afonso da. Curso de Direito Constitucional Positivo. Ed. 25. São Paulo: Malheiros, 2005. 